\title{
Impact of Area Enclosures on Density and Diversity of Large Wild Mammals: The Case of May Ba'ati, Douga Tembien District, Central Tigray, Ethiopia
}

\author{
Mastewal Yami ${ }^{1 *}$, Kindeya Gebrehiwot ${ }^{1}$, M. Stein ${ }^{2}$, and Wolde Mekuria ${ }^{1}$ \\ ${ }^{1}$ Department of Land Resources Management and Environmental Protection, Mekelle University, \\ P O Box 231, Mekelle, Ethiopia \\ ${ }^{2}$ University of Life Sciences, Norway
}

\begin{abstract}
In Ethiopian highlands, area enclosures have been established on degraded areas for ecological rehabilitation. However, information on the importance of area enclosures in improving wild fauna richness is lacking. Thus, this study was conducted to assess the impact of enclosures on density and diversity of large wild mammals. Direct observations along fixed width transects with three timings, total counting with two timings, and pellet drop counts were used to determine population of large wild mammals. Regression analysis and ANOVA were used to test the significance of the relationships among age of enclosures, canopy cover, density and diversity of large wild mammals. The enclosures have higher density and diversity of large wild mammals than adjacent unprotected areas. The density and diversity of large wild mammals was higher for the older enclosures with few exceptions. Diversity of woody species also showed strong relationship $\left(\mathrm{r}^{2}=0.77\right.$ and 0.92$)$ with diversity of diurnal and nocturnal wild mammals. Significant relationship (at $\mathrm{p}<0.05)$ was observed between age and density as well as among canopy cover, density and diversity of large nocturnal wild mammals. The existence of both large carnivore and herbivore wild mammals indicated the effectiveness of area enclosures in biodiversity conservation. However, for further improvement of the habitat and thereby biodiversity, development of water points and vegetation management are timely needed.
\end{abstract}

Key words: Area Enclosure; Density; Diversity; Ethiopia; Large Wild Mammal

\section{Introduction}

Ethiopia is renowned for its richness in biodiversity. The biological diversity is made up of an estimated total of 6500-7000 plant species of which 12 are endemic. There are also 255 identified mammals, 861 birds, 201 reptiles, 63 amphibians, 150 fish and 324 butterfly species of which 31 mammals and 16 birds are endemic (Groombridge and Jenkins, 1994; EWNHS, 1996; FDRE, 2001). The degradation of these resources is widespread and severe. The major causes include land clearing for agriculture and lack of recognition of the roles and rights of local communities in the conservation and use of biological resources (FDRE, 2001).

Tigray contains many of the areas of greatest land degradation concern in Ethiopia's highlands (Fitsum et al., 1999). The natural forest of the region has been destroyed mainly through encroachment of subsistence cultivation. Crop production and animal husbandry potential of the region has declined severely mainly due to the degradation of natural resources (Tassew 1995; Wolde , 2004).

However, Tigray is known not only for the severity of land degradation but also since the last few years, for the concerted efforts taking place there to redress these problems including construction of stone terraces and soil bunds, area enclosure and afforestation (Fitsum et al., 1999). In the places where area enclosures are established particularly in the Northern part of the country, area enclosures are among the green spots with considerable species diversity (TIC, 1999; Tefera , 2001; Betru et al., 2005).

In enclosures, it is generally believed that all the land resources will be protected from degradation. Although the restoration and buffering effects of area enclosures have been well studied (Kindeya , 2003; Aerts et al., 2004, and Descheemaker et al., 2005), there is no study that offers quantitative information that helps to compare area enclosures with the unprotected areas with respect to wild fauna. Therefore, this study is initiated to generate quantitative information and thereby to see whether area enclosures have impact on the density and diversity of large wild mammals or not.

\section{Materials and Methods}

\subsection{Description of the Study Area}

Enclosures with ages 8, 10, 22, 29 years and a church forest were selected at May Ba'ati, located in Douga Tembien Wereda(district), central Tigray, Ethiopia (Figure 1). 


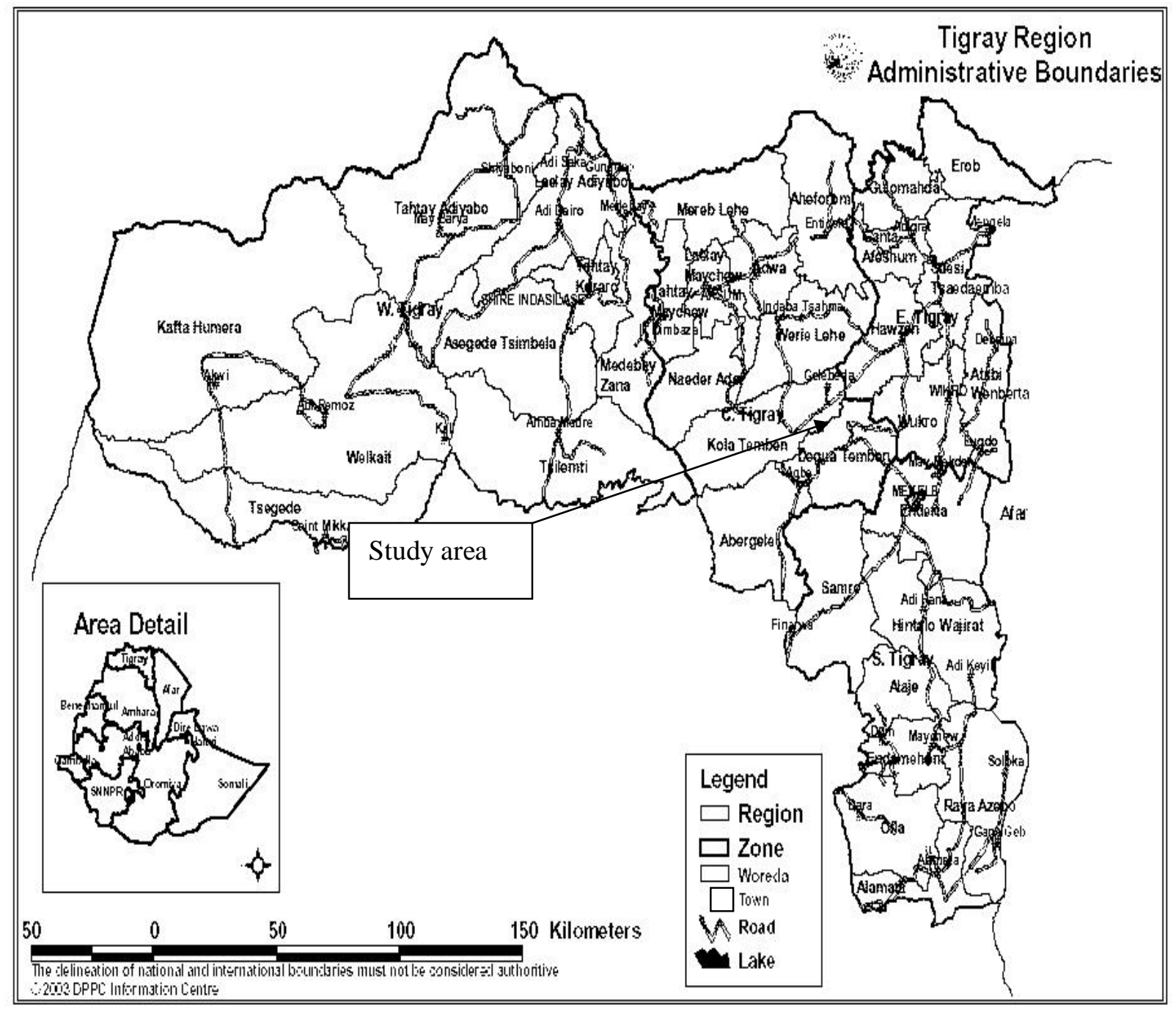

Figure 1. Location of the study area (Source:http:www.reliefweb.int/rw/rwb.nsf/0/adbeaa25dfc96d21c1256f2d004849f2?opendocument)

May Ba'ati $\left(13^{\circ} 38^{\prime} 52^{\prime \prime} \mathrm{N}, 39^{\circ} 13^{\prime} 15^{\prime \prime} \mathrm{E}\right)$ is situated at altitude ranging from 2300 to $2380 \mathrm{~m}$ a. s. 1. The population is mainly rural, as is more than $90 \%$ of the Ethiopian population (Nyssen, 2001). The study area falls in the boundary between the "dry weyna dega" and "moist dega" (Sarah , 2003). Mean annual rainfall in the study area is $700 \mathrm{~mm}$. There are natural springs that serve as source of drinking water for the dwellers and their cattle.

Euclea racemosa subsp. schimperi, Dodonea angustifolia, Acacia etbaica, and Acokanthera schimperi are the abundant plant species in the study area. Acacia saligna and Eucalyptus tereticornis were some of the introduced species. There are varied species of birds, mammals, reptiles, amphibians, and invertebrates. Some of the common large wild mammals include Crocuta crocuta and Canis aureus. The major land uses are enclosures of different ages, farmland, degraded grazing land and church forest. The main soil units are Calcisols, Cambisols and Phaeozems (FAO, 1998).

\subsection{Experimental Design}

In all the study sites, fixed width line transect were set to assess the density and diversity of large diurnal wild mammals (Figure 2). 



\section{May Ba' ati}

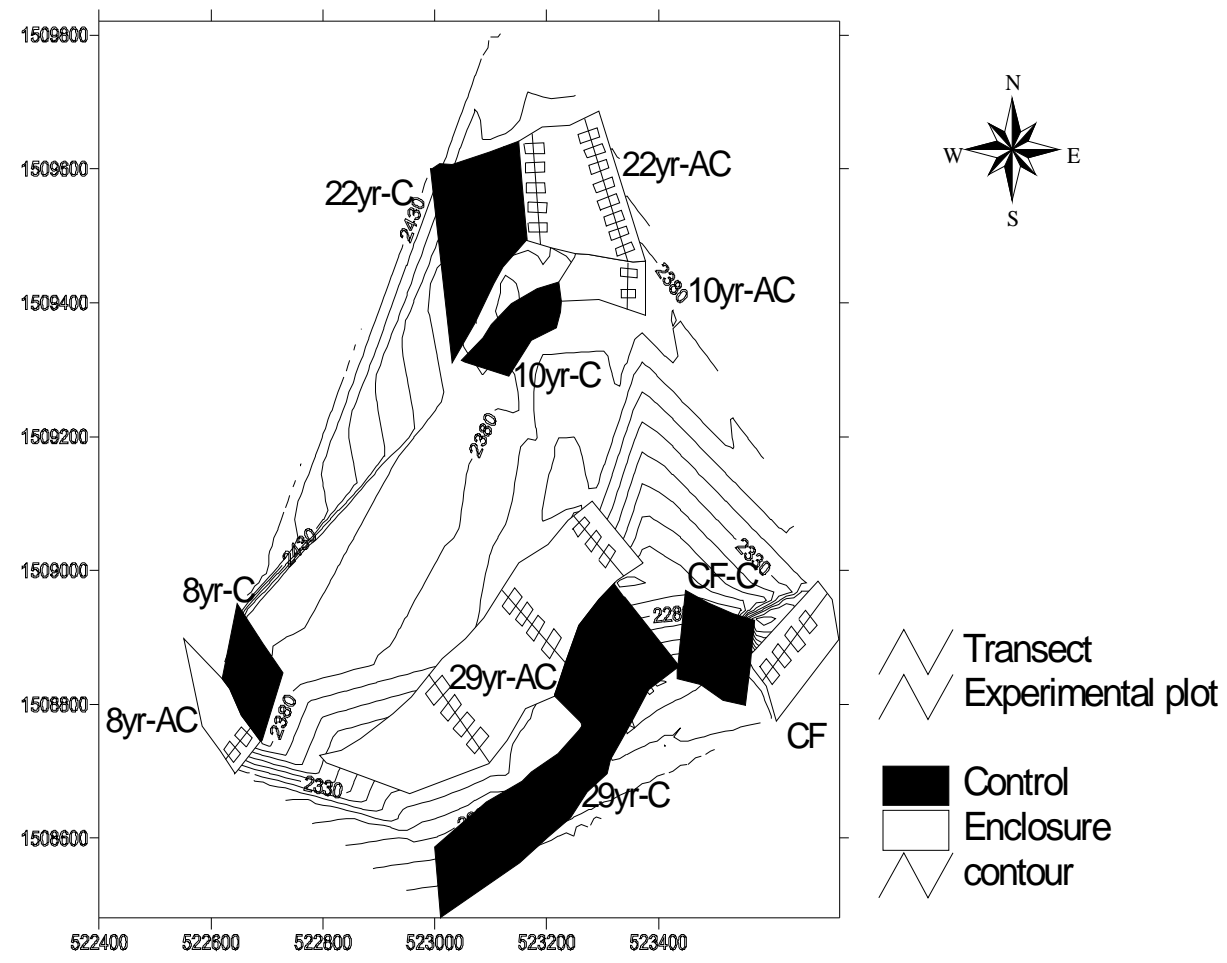

$\begin{array}{rrr}0.6 & 0 & 0.6 \text { Kilometers }\end{array}$

Figure 2. Design of the experiment $(\mathrm{AC}=$ area enclosure, $\mathrm{CF}=$ church forest, and $\mathrm{C}=$ control $)$

Transect width and distance between consecutive transects were $100 \mathrm{~m}$ and $150 \mathrm{~m}$ respectively. Three timings: 10a.m. (morning), 12a.m. (noon), and 6p.m. (dusk) were specified for census of large diurnal wild mammals. For counting large nocturnal wild mammals, timings were 8p.m. and 4a.m. (night and dawn, respectively). These timings are selected for they are the usual hours observed in which the large wild mammals come out of their homes to search for food and water.

Monitoring datasheets were prepared to record the name, number, distance and time traveled of transect, type of habitat, mean sighting distance and global position of the large wild mammals observed in each of the timings.

\subsection{Data Collection}

\subsubsection{Direct Methods: Animal Census}

Direct observations were conducted along the fixed transect widths for large diurnal wild mammals.
Each observation lasted for an hour. Binoculars with $10 * 25$ magnifying power were used for clear observation.

Total counts technique was used to assess the density and diversity of large nocturnal wild mammals. The footpaths along which the animals come out of their homes were followed for each of the large wild mammals in the area enclosures. The counting was conducted at the two specified timings. Each of the timings lasted for two consecutive hours. The counting was undertaken for 5 consecutive days.

\subsubsection{Indirect Method}

The fecal droppings of large wild mammals were collected along the transect widths. Photograph trapping of each pellet drops were undertaken and the pellet drops were identified (Figure 3). 

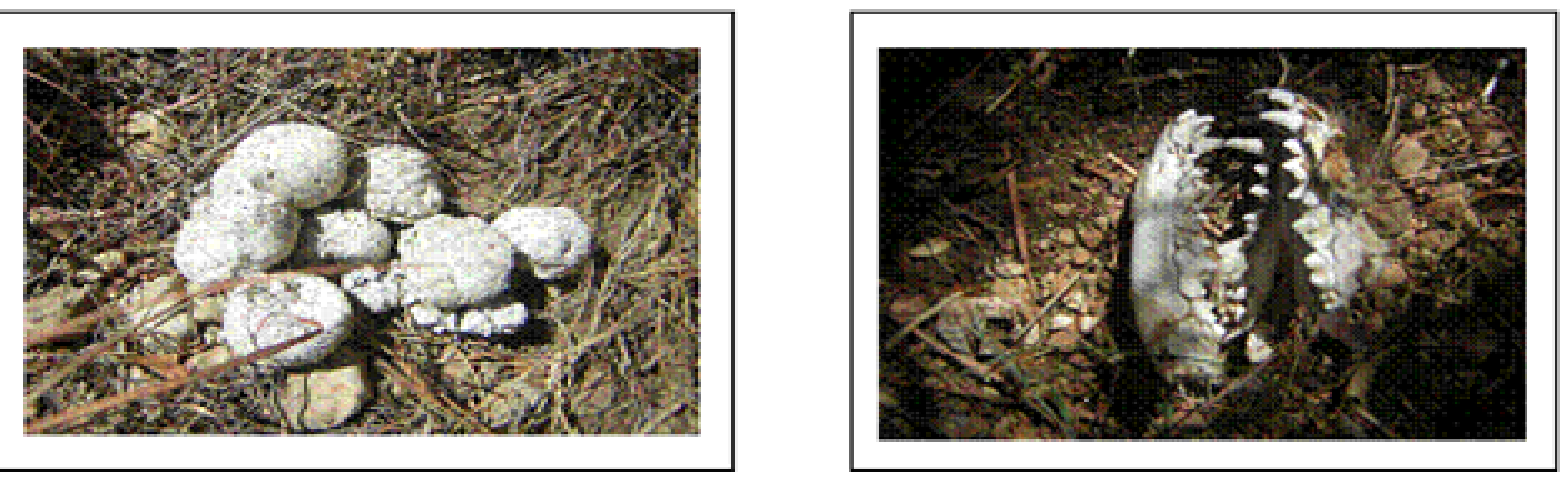

Figure 3 Pellet drops of Crocuta crocuta (left) Canis aureus (right)

In pellet group counting method, the large wild mammals are not counted but something associated with them. Although this method has limitations related to knowing the rate of defecation, locating all the piles of pellets, and accurately identifying and aging the pellets, it was used to supplement and validate the direct methods of animal counting.

\subsection{Data Analysis}

The densities of large wild mammals were calculated by using the formula (Teshale , 2003).

$$
\begin{aligned}
& O\left(K m^{2}\right)=(K \times S \times 2) K m^{2} \\
& D\left(\frac{N o}{K m^{2}}\right)=\frac{N}{O} \quad P\left(\frac{N o}{h a}\right)=\frac{N}{O} \times H
\end{aligned}
$$

Where: $\mathrm{O}=$ observed area $\left(\mathrm{Km}^{2}\right), \mathrm{K}=$ length of transect $(\mathrm{Km}), \mathrm{S}=$ sighting distance on either side of the transect $(\mathrm{Km}), \mathrm{D}=$ density of the large wild mammals, $\mathrm{N}=$ number of large wild mammals in the observed area, $\mathrm{H}=$ size of the whole conservation area, and $\mathrm{P}=$ total population size.

The sampling intensity ranges from $54 \%$ to $98 \%$. For the total counting method, the abundance of large wild mammals for the two timings was calculated on per hectare basis. In the indirect method of estimating abundance, the weighted averages of pellet groups along transects were taken for each site. Then, the population of species is estimated for the season. Each season (summer, spring, winter, and autumn) was taken to have 90 days, as there are 4 seasons each lasting for 3 months in Ethiopia.
Regression analysis was used to see the significance of the relationships among age of area enclosure, canopy cover, density and diversity of large wild mammals. Density and diversity of large wild mammals were taken as dependent variables while age and canopy cover were taken as independent variables. Measures of variations such as coefficient of variation (CV) and standard error of means were used to see the variability among transect means within a site. Analysis of variance (ANOVA) was also used to test the significance of the relationships between dependent and independent variables.

Relationships among diversity of woody species with density and diversity of large wild mammals; density and diversity of large herbivore and carnivore wild mammals; direct and indirect methods of animal counting; and size of enclosures and density and diversity of large wild mammals were established. Fitting curves were drawn to see the correlation coefficient $\left(\mathrm{r}^{2}\right)$ of the relationships.

\section{Results and Discussion}

\subsection{Density and Diversity of Large Diurnal Wild Mammals}

The density of large wild mammals varied from species to species among the enclosures. The 29-year enclosure had relatively the highest density of large wild mammals while the eight-year enclosure had the lowest. The species diversity in the 10-year enclosure was the same as that of the 22-year enclosure. However, there were fewer large wild mammals in the 10-year enclosure (Table 1). 
Table 1. Large diurnal wild mammals of the land uses

\begin{tabular}{|c|c|c|c|c|c|c|}
\hline Land use & $\begin{array}{l}\text { Church } \\
\text { forest }\end{array}$ & 29-year AC & 22-year AC & 10 -year AC & 8-year AC & $\begin{array}{l}\text { Unprotected } \\
\text { areas }\end{array}$ \\
\hline Species name & No./ha & No./ha & No./ha & No./ha & No./ha & No./ha \\
\hline Procavia capensis & 2.0 & 4.0 & 0 & 0 & 0 & 0 \\
\hline Lepus capensis & 0.5 & 8.0 & 9.0 & 2.0 & 1.0 & 0 \\
\hline Canis aureus & 1.0 & 10.0 & 5.0 & 1.0 & 0 & 0 \\
\hline Caracal caracal & 1.0 & 2.0 & 0.0 & 0 & 0 & 0 \\
\hline Number of species & 4 & 4 & 2 & 2 & 1 & 0 \\
\hline $\begin{array}{l}\text { Total number of } \\
\text { individuals }\end{array}$ & 4.5 & 24 & 14 & 3 & 1 & 0 \\
\hline $\mathrm{CV}$ of transect means & - & $129.87 \%$ & $20.14 \%$ & - & - & - \\
\hline $\begin{array}{l}\text { Std. Error of transect } \\
\text { means }\end{array}$ & - & 6.00 & 1.00 & - & - & - \\
\hline F value $\quad$ age $\mathrm{o}$ & \multicolumn{6}{|c|}{ age of enclosure vs. density $=0.21^{\mathrm{ns}}$; age of enclosure vs. diversity $=1.66^{\mathrm{ns}}$} \\
\hline
\end{tabular}

The variation in the density and diversity of large wild mammals among the land uses could arise from the variation in factors such as food, cover, breeding site, degree of disturbance, type of habitat, and the location of enclosures. A study conducted by Bolen and Robinson (1999) had given similar explanation to such variation. The highest species diversity of the 29-year enclosure could be explained by the presence of rugged habitats that can aid the wild animals to get food, shelter and breeding sites. The presence of water point in the church forest and the relatively little disturbance could contribute to its species richness when compared to the younger enclosures. The big variability among transect means (Table1) in the 29-year enclosure can be explained by the difference in the position of transects and specific site situation (Mastewal , 2006).
The church forest was expected to have the largest animal population for it is $>1000$ years old and relatively undisturbed (Sarah , 2003). But the wild animals usually prefer rugged environments that can provide varied types of niches rather than the one that is dominated by large trees (Kumar, 1986; Johnson and Walter, 2000). Besides, the relatively small size (2.66 ha) of the church forest could also contribute for the low population of large wild mammals. The lower density and diversity of the 10-year enclosure could result from the disturbance created since the enclosure is located near a road. In addition, there is visible interference (Figure 4) of people and domestic animals in it.

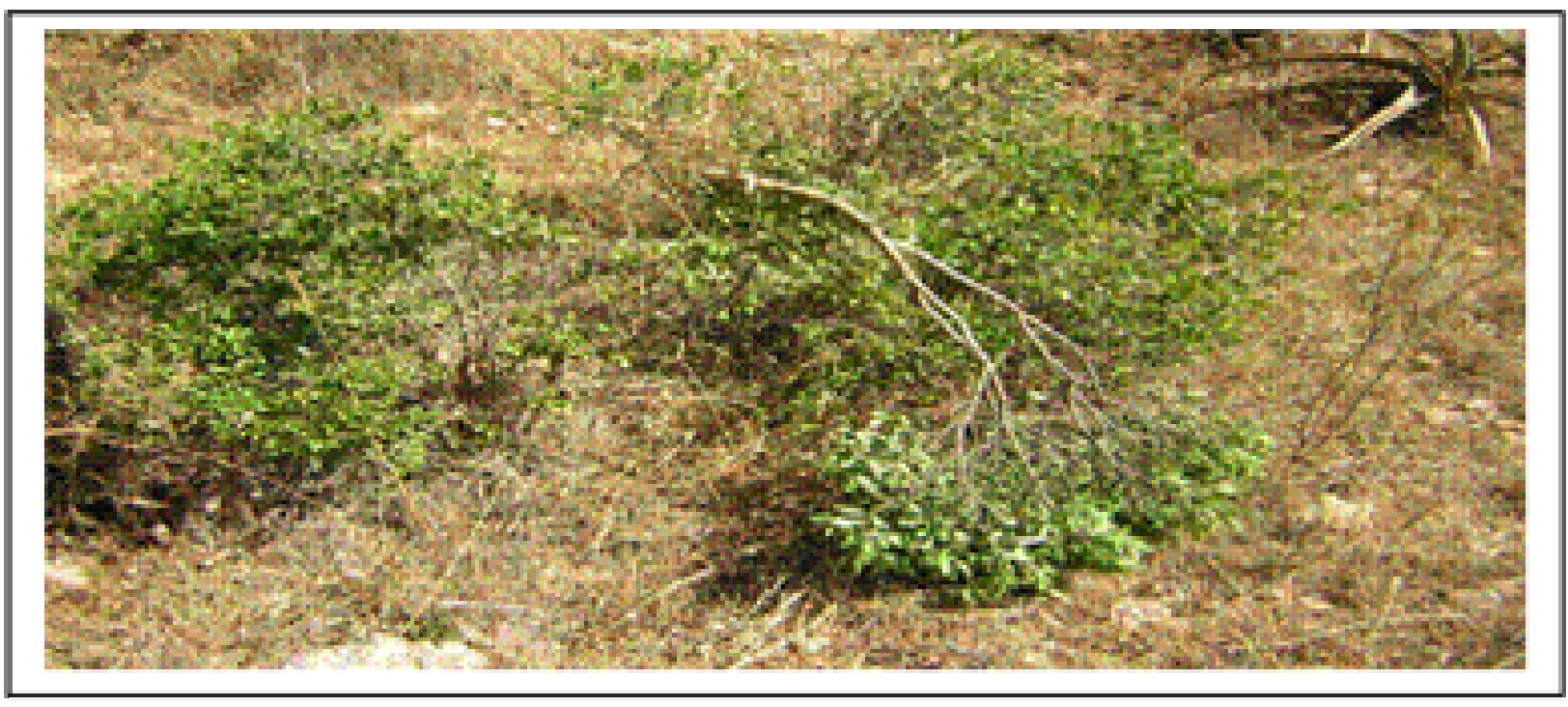

Figure 4 Human interference in enclosures of the study area 
For most species, partial correlation analysis revealed positive correlation ( $\mathrm{r}=0.31,0.31$ and 0.33 ) between age of area enclosure and density of large diurnal wild mammals. But negative correlation $(\mathrm{r}=-0.26)$ was found for Canis aureus. This could arise from the difference in habitat requirements among the large wild mammals. It also revealed a positive correlation $(\mathrm{r}=$ 0.597) between age and diversity. However, both relationships were not significant (at $\mathrm{p}<0.05$ ).

\subsection{Density and Diversity of Large Nocturnal Wild Mammals}

The species diversity in the church forest and the 29-year enclosure were almost the same (Table 2).

Table 2 Large nocturnal wild mammals of the land uses

\begin{tabular}{|c|c|c|c|c|c|c|}
\hline Land use & $\mathrm{CF}$ & $\begin{array}{c}\text { 29-year } \\
\text { AC }\end{array}$ & $\begin{array}{c}\text { 22-year } \\
\text { AC }\end{array}$ & $\begin{array}{c}\text { 10-year } \\
\text { AC }\end{array}$ & $\begin{array}{c}\text { 8- year } \\
\text { AC }\end{array}$ & $\begin{array}{c}\text { Unprotected } \\
\text { areas }\end{array}$ \\
\hline Species name & No./ha & No./ha & No./ha & No./ha & No./ha & No./ha \\
\hline Hystrix cristata & 1.68 & 0.43 & 0.09 & 0 & 0.19 & 0 \\
\hline Mellivora capensis & 0.38 & 0.02 & 0 & 0 & 0 & 0 \\
\hline Ictonyx striatus & 0.27 & 0.05 & 0 & 0 & 0.10 & 0 \\
\hline Crocuta crocuta & 0.84 & 0.36 & 0 & 0 & 1.36 & 0 \\
\hline Leptailurus serval & 0.08 & 0.02 & 0 & 0 & 0 & 0 \\
\hline Civettictis civetta & 0.11 & 0.02 & 0 & 0 & 0 & 0 \\
\hline Galerella sanguinea & 0 & 0.08 & 0 & 0 & 0 & 0 \\
\hline Number of species & 6 & 7 & 1 & 0 & 3 & 0 \\
\hline $\begin{array}{l}\text { Total number of } \\
\text { individuals }\end{array}$ & 3.36 & 0.98 & 0.09 & 0 & 1.65 & 0 \\
\hline $\mathrm{F}$ value & \multicolumn{6}{|c|}{ age of enclosure vs. density $=10.06^{*}$; age of enclosure vs. diversity $=0.93^{\text {ns }}$} \\
\hline
\end{tabular}

The density of the large wild mammals in the church forest was the highest of the land uses; especially Hystrix cristata (porcupine) was found to be highly abundant in the church forest. This indicates that the habitat could be suitable for this species in terms of its requirements such as food and shelter.In the 10-year enclosure, no large wild mammal was observed (Table 2).The 10-year enclosure could not be suitable for the large nocturnal wild mammals due to absence of varied habitats and intense human interference. The eight-year enclosure had a remarkable density and diversity of large nocturnal wild mammals. This can be explained by the potential of the site to provide hiding places for nocturnal species because the enclosure has high stone cover and is located at a relatively far distance from human residence.

Partial correlation analysis revealed positive correlation $(r=0.88)$ between age of area enclosure and density of large nocturnal wild mammals. Besides, it revealed positive correlation $(r=0.488)$ between age and diversity. Although the relationship between age and diversity is not significant $(\mathrm{p}>0.05)$, both regression and analysis of variance showed a significant relationship $(\mathrm{p}<0.05)$ between age and density.

\subsection{Indirect Estimation of Density and Diversity of Large Wild Mammals}

The indirect method also showed that the density and diversity of species varied among the land uses. The church forest, 29-year and 22-year enclosures had higher density and diversity of large wild mammals than the 10 and eight-year old enclosures. No pellet drops of large wild mammals were encountered in the adjacent unprotected areas (Table 3). 
Table 3. Fecal drop counts of the land uses

\begin{tabular}{lcccccc}
\hline \multicolumn{1}{c}{ Land use } & CF & $\begin{array}{c}29-\text { year } \\
\text { AC }\end{array}$ & $\begin{array}{c}\text { 22-year } \\
\text { Species name }\end{array}$ & $\begin{array}{c}\text { AC-year } \\
\text { PC }\end{array}$ & $\begin{array}{c}\text { 8-year } \\
\text { AC }\end{array}$ & $\begin{array}{c}\text { Unprotected } \\
\text { areas }\end{array}$ \\
\cline { 2 - 7 } & season & $\begin{array}{c}\text { P/ha- } \\
\text { season }\end{array}$ & $\begin{array}{c}\text { P/ha- } \\
\text { season }\end{array}$ & $\begin{array}{c}\text { P/ha- } \\
\text { season }\end{array}$ & $\begin{array}{c}\text { P/ha- } \\
\text { season }\end{array}$ & P/ha-season \\
\hline Canis aureus & 0.27 & 0.07 & 0.06 & 0.58 & 0.06 & 0 \\
Procavia capensis & 0.02 & 0 & 0 & 0 & 0 & 0 \\
Crocuta crocuta & 0.01 & 0.04 & 0.02 & 0.01 & 0.05 & 0 \\
Hystrix cristata & 0.03 & 0.01 & 0 & 0 & 0 & 0 \\
Caracal caracal & 0 & 0.01 & 0.01 & 0.03 & 0 & 0 \\
Lepus capensis & 0 & - & 0.01 & 0 & 0 & 0 \\
CV of P/ha-season & - & $58.48 \%$ & $15.55 \%$ & - & - & - \\
among transects & & & & & & - \\
Std. Error of P/ha- & - & 0.05 & 0.01 & - & - & - \\
season & & & & & &
\end{tabular}

$\overline{A C}=$ area enclosure, $C F=$ church forest,$P=$ population, and $C V=$ Coefficient of variation for study sites having greater than one transect

Both direct and indirect methods revealed that the density and diversity of species were higher for the older enclosures and the church forest with few exceptions. Big variability of total population among transects (Table 3) in the 29-year enclosure was also revealed by the indirect method. However, the effectiveness of the two methods in estimating the density of large wild mammals varied from species to species as it is shown by the correlation values of the relationship between them (Figure 5).

This could arise from the difference in the behavior of the wild species like sensitivity to human disturbance and selection of sites for defecation. Studies conducted by Fay (1991) and Srikosamatara (1993) also explained that wild animals vary in behavior and this could have an implication in the effectiveness of the different methods of animal counting.

\subsection{Relationship Between Large Herbivore and Carnivore Wild Mammals}

In the study, both large carnivore and herbivore wild mammals were encountered which have different impact on the food resources available. Species like Procavia capensis (hyrax) and Hystrix cristata feed on plant parts mainly roots and insects associated with roots. Others such as Lepus capensis (hare) feed mainly on grasses. Large carnivore wild mammals namely
Crocuta crocuta, Caracal caracal (caracal), Leptailurus serval (serval cat) were also encountered. The presence of heterogeneous microhabitats in a site helps organisms to coexist being incorporated in different niches (Kumar, 1986; Yosef , 1998). The abundance of large carnivore wild mammals depends on the availability of prey and suitability of other physical and behavioral factors. As they are both components of food chain, the presence of herbivores and carnivores are highly interlinked since one affects the abundance of the other. If carnivores dominate an area, the number of herbivores will be reduced. If the dominant species are herbivores, the available food resource will be consumed exceeding the production. Because each of the various links in food chain is a clear reference to the method by which energy and matter normally move through ecosystems (Schaller, 1967, 1972; Smuts, 1978; Rabinowitz and Walker, 1991; Bolen and Robinson, 1999).

In the study, the herbivore-carnivore density and diversity correlation values were higher for both large diurnal and nocturnal wild mammals (Figure 6 and 7). 

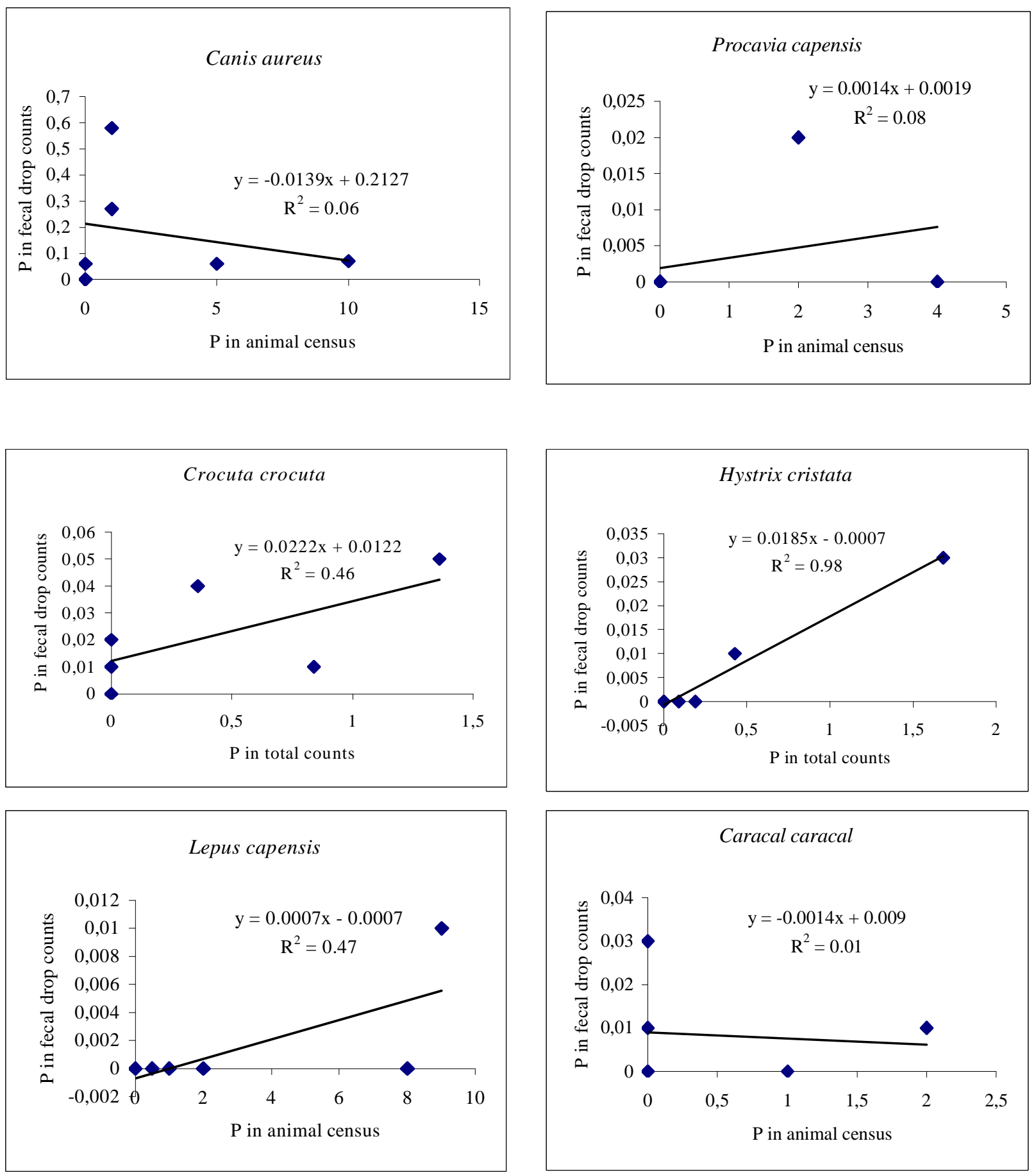

Figure 5. Relationship between direct and indirect methods of animal counting; P (No./ha) 

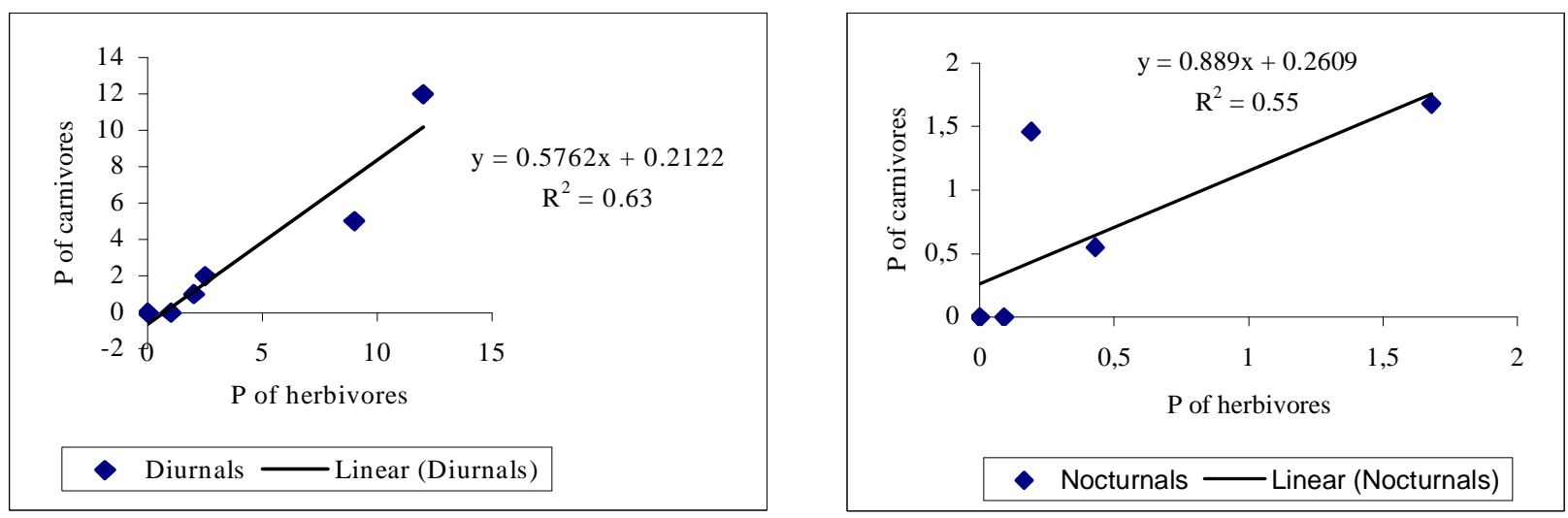

Figure 6. Relationship between density (No./ha) of herbivores and carnivores for large diurnal (left) and nocturnal (right) wild mammals
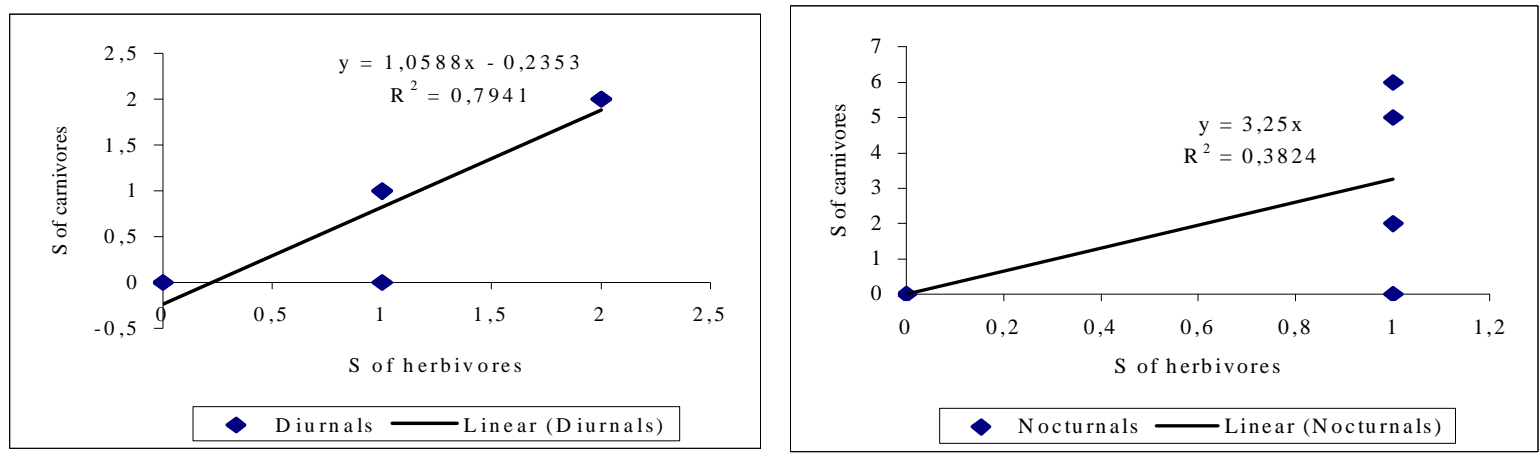

Figure 7. Relationship between diversity of herbivores and carnivores for large diurnal (left) and nocturnal (right) wild mammals

This could be explained by the improved vegetation status of the area which in turn improves the density and diversity of herbivores. A study conducted by Johnson and Walter (2000) also indicated that the food management activities will usually focus on herbivores. By improving the habitat quality for herbivores, their numbers may increase, thus improving the food supply for carnivores. The regular presence of carnivores is a good indication of successful management for prey species.

Table 4. Canopy cover estimates of the land uses

\subsection{Relationship Between Large Wild Mammals and Canopy Cover}

The density and diversity of large diurnal wild mammals was highest for the 29-year enclosure and the church forest, followed by the 22-year, 10-year and eight-year enclosures. The canopy cover estimates (Table 4)

\begin{tabular}{lc}
\hline Land uses & Estimated canopy cover (\%) \\
\hline CF & 55.53 \\
$29-y r$ AC & 38.00 \\
$22-y r$ AC & 21.91 \\
$10-y r$ AC & 2.05 \\
Eight-yr AC & 18.5 \\
Unprotected areas & 0 \\
\hline
\end{tabular}

$A C=$ area enclosure, $C F=$ church forest 
showed that vegetation improvement does not always increase with age since canopy cover estimate was higher for the eight-year enclosure than the 10-year enclosure. This could be explained by the anthropogenic and physical factors that can affect the effectiveness of the management.

The density and diversity of large wild mammals was higher for the old aged enclosures with few exceptions. Positive correlations $(\mathrm{r}=0.292,0.812 ; \quad \mathrm{r}=0.797$, 0.863 ) were found for the relationships of canopy cover with density and diversity of large diurnal and nocturnal wild mammals respectively. The relationships among canopy cover, density, and diversity of large nocturnal wild mammals were significant $(\mathrm{p}<0.05)$. This result was also verified by the relatively higher correlation coefficient $\left(r^{2}\right)$ for the relationships among canopy cover, density and diversity of large nocturnal wild mammals (Figure 8).
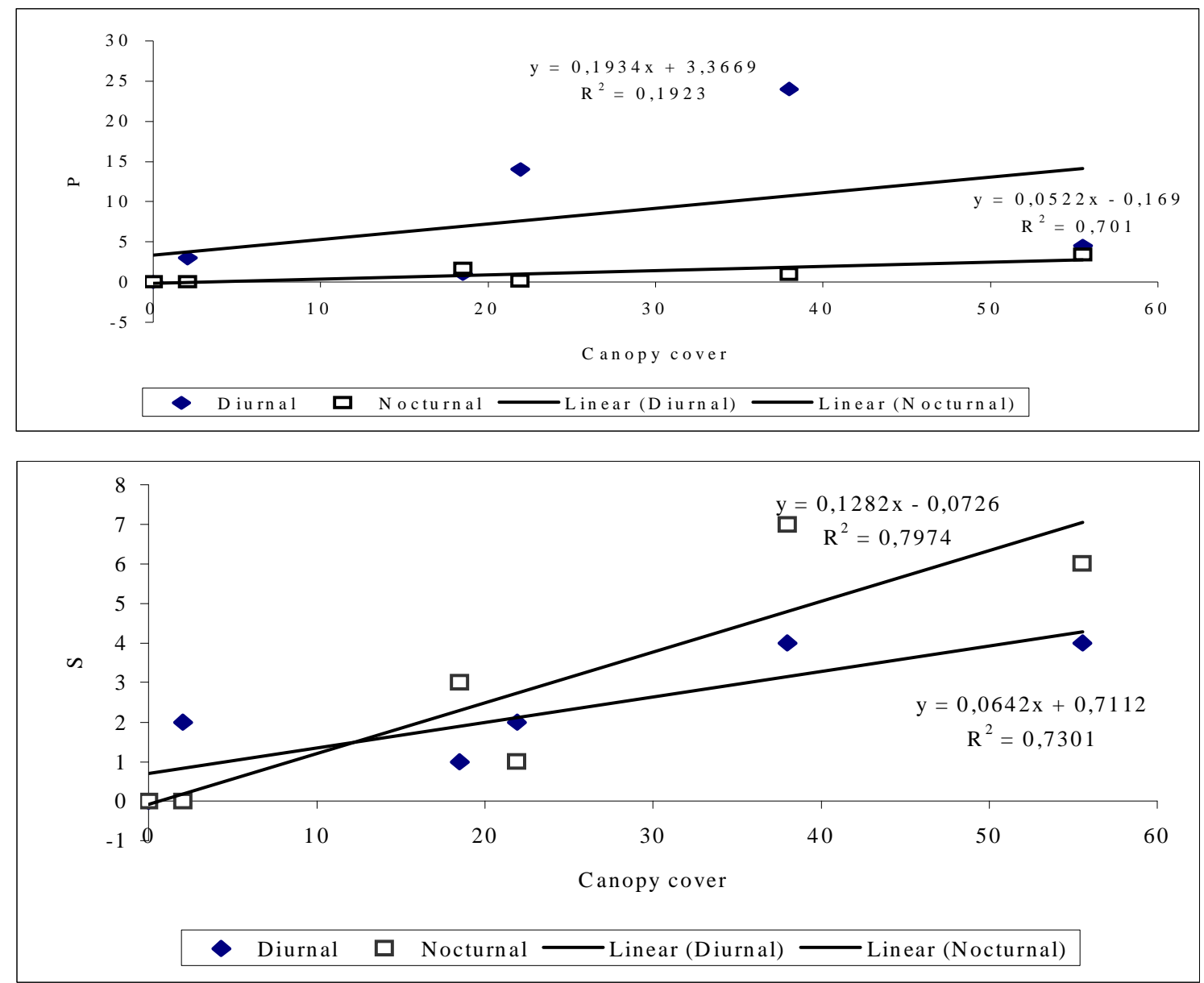

Figure 8. Relationships among canopy cover, density and diversity of large wild mammals

The lower density and diversity of large nocturnal wild mammals in the 10-year enclosure could be due to the absence of rugged microhabitats (Yosef , 1998). Besides, although in many cases the older enclosures are rich in both plant and large wild mammal composition, the physical and human-related factors could affect both vegetation and large wild mammal density and diversity.

Large wild mammals respond to cover changes. The vegetation cover of an area affects the number of individuals that can be supported by the site. This could be due to the importance of cover in providing shelter, food, nesting opportunities, and protection from predators (Baxter et al., 2005). Bolen and Robinson (1999) also concluded that any factor that has an impact on the composition of plant species is expected to affect the type and population of wild fauna that can be supported by the habitat. Besides, many of the wildlife species found in the forest have very specific cover needs during their lifetime (Johnson and Walter, 2000). Also, an animal's cover needs change with season. 


\subsection{Relationship Between Diversity of Woody Species and Large Wild Mammals}

The relationship between diversity of woody species and large wild mammals was relatively strong than the relationship between diversity of woody species and density of large wild mammals (Figure 9).
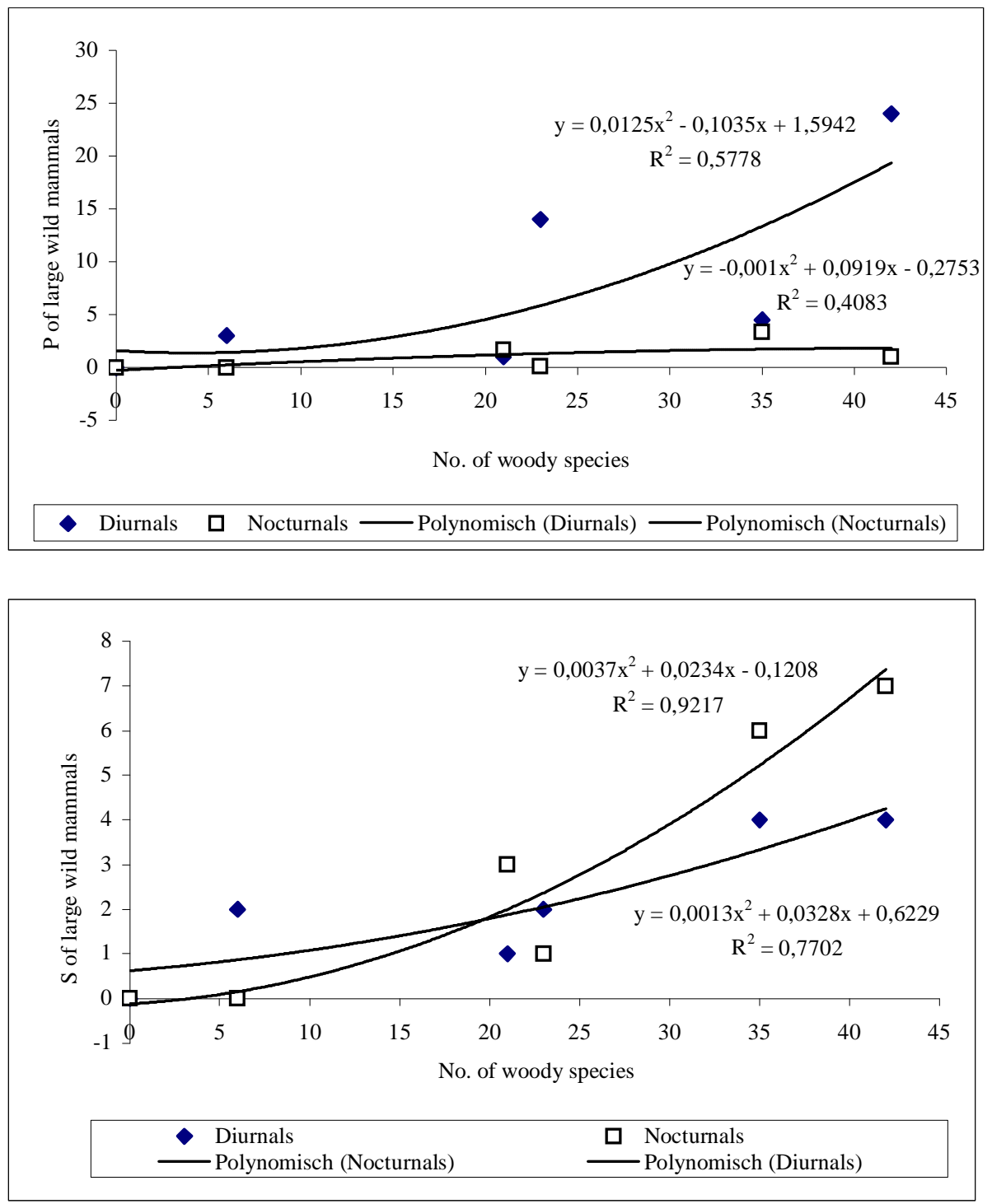

Figure 9. Relationship among number of woody species and density and diversity of large wild mammals

This could be explained by the presence of varied food resources that can meet the demand of different large wild mammals.

The relatively lower correlation values between number of woody species and density of large wild mammals could result from the inadequate food resources. It is also indicated in researches that wild animals usually eat the most nutritious and palatable foods that are available in their habitat (Johnson and Walter, 2000). Both the quantity and quality of food in a site have an impact on the density and diversity of large wild mammals (Karanth and Sunquist, 1992;
Bolen and Robinson, 1999). In addition, the structure, composition and function of plant communities change with time. The way in which vegetation is managed has an important influence on its value as a habitat in the long term (Bennett et al., 2005).

\subsection{Relationship Between Size of Enclosures and Density and Diversity of Large Wild Mammals}

In most cases, the density and diversity of large wild mammals encountered in the study increased with the size of the enclosures. This is because larger enclosures have more different kinds of habitats and support larger 
populations. Valone and Hoffman (2003) also indicated that only larger patches are likely to contain enough habitats to support species like larger mammals that require larger areas.

The study also revealed that the relationship between size of enclosures and density and diversity varies among large diurnal and nocturnal wild mammals. The density and diversity of large diurnal wild mammals showed strong relationship with size of the habitat (Figure 10).
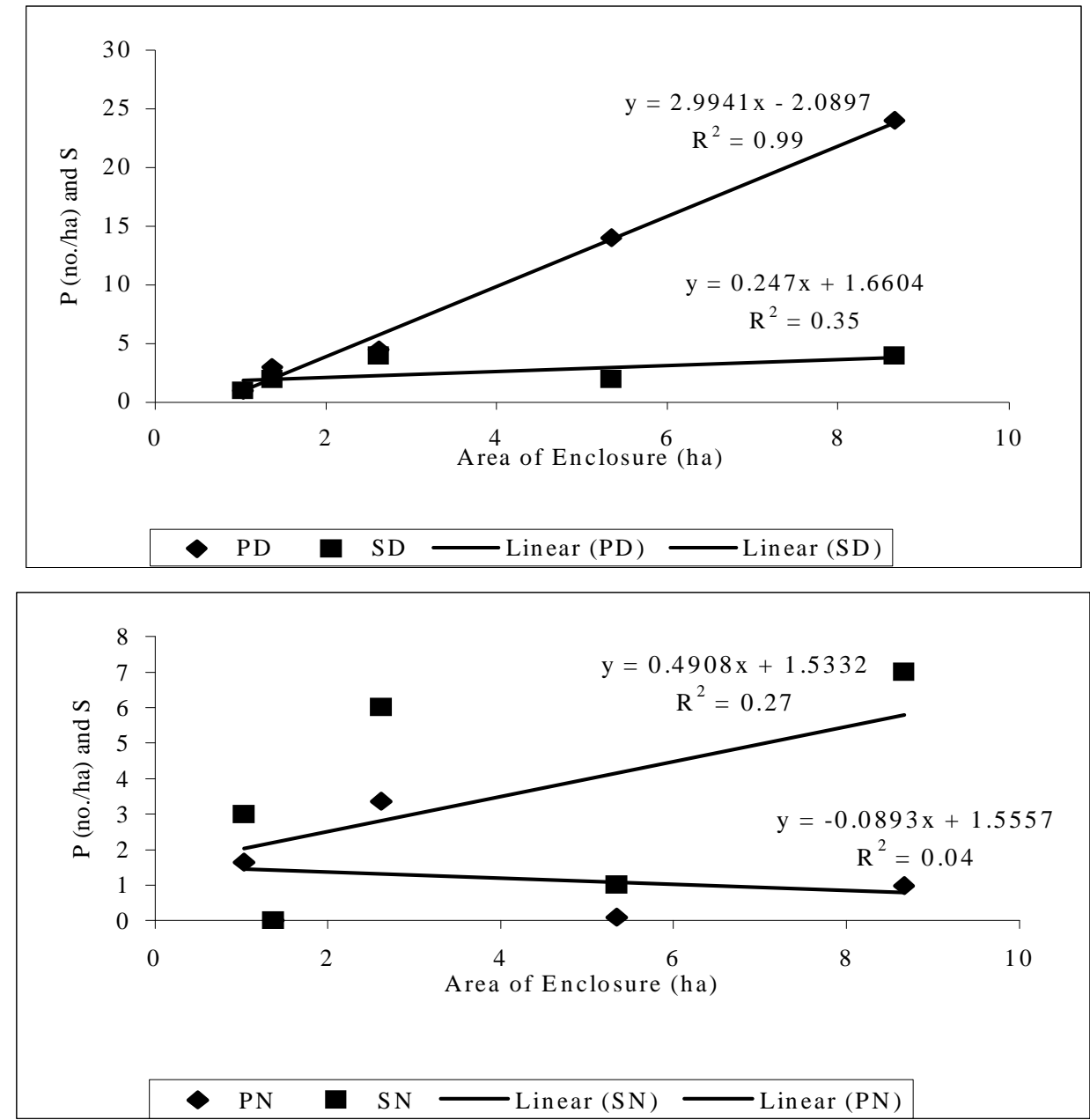

Figure 10. Relationship between size of enclosures with density and diversity of large diurnal and nocturnal wild mammals where: PN, SN, PD, and SD are density and diversity of large nocturnal and diurnal wild mammals respectively

This variation could arise from the difference in sensitivity towards the size and type of the habitat. Studies conducted on wild animals suggest that the effect of patch size may be species dependent (Foster and Gaines, 1991). Many species are area sensitive, which means that they are absent from or rare in small patches of habitat and more abundant within extensive areas of undeveloped land. Besides, some surveys (Cody, 1975) have investigated the hypothesis that animal species diversity increases with increasing habitat complexity, because more complex habitats offer greater variety of niches for different species, therefore harbour higher diversity of fauna.

\section{Conclusions}

The density and diversity of large wild mammals varied among land uses. This could result from the variation in ruggedness, resource availability, and interference among the land uses. It is observed that the older enclosures have higher density and diversity of large wild mammals than the younger enclosures and adjacent unprotected areas. The study also revealed that relationship exists between size of enclosures and density and diversity of large wild mammals. The existence of both large carnivore and herbivore wild mammals indicated the effectiveness of area enclosures 
in biodiversity conservation. However, for further improvement of the habitats and thereby biodiversity, development of water points and vegetation management are timely needed. There is a need of further research on the relationship between size and shape of enclosures with species richness. In addition, researches that generate quantitative information on other wild faunal groups are timely needed so that the potential of enclosures in biodiversity conservation can be quantified.

\section{Acknowledgements}

We are thankful to Institutional Union Cooperation (IUC) between Mekelle University and K.U Leuven Universität for funding the research. We would like to acknowledge Ermias, Emiru, Aklilu, Zelalem and Daniel for their help throughout the study.

\section{References}

Aerts, R., Wagendrop, T., November, E., Mintesinot B., Deckers, J., Muys, B. 2004. Ecosystem thermal buffer capacity as an indicator of the restoration status of protected areas in the Northern Ethiopian Highlands. Restoration Ecology 12: 586-596.

Baxter, G., Spencer, R., Cavanough, V., and Kennedy, M. 2005. Adult free zones in Australian small mammal populations: Response of Australian native rodents to reduced cover. Austral Ecology 30 (8): 868-876.

Bennett, A., Kimber, S., and Ryan, P. 2005. Revegetation and Wildlife: A Guide to Enhancing Revegetation Habitats for Wildlife Conservation in Rural Environments. Bushcare National and Research and Development Program Research Report 2/00. Australia. Common Wealth of Australia.

Betru, N., Jawad, A., and Ingrid, N. 2005. Exploring Ecological and Socio-Economic Issues for the Improvement of Area Enclosure Management. A Case Study from Ethiopia. Dryland Coordination Group Report No. 38. Oslo, Norway. pp. 63. http://www.drylandsgroup.org. (accessed on 25/08/2006).

Bolen, G., and Robinson, L. 1999. Wildlife Ecology and Management. $4^{\text {th }}$ Edition. USA. Prentice-Hall, Inc. pp. 482.

Cody, M. 1975. Towards a theory of continental species diversity. In: Cody, M. and Diamond, J. (eds.). Ecology and evolution of communities. Belknap, Cambridge, Massachusetts, USA.

Deschemaeker, K., Nyssen, J., Rossi, J., Poesen, J., Mitiku H., Moeyerson, J., Deckers, J. 2005. Sediment deposition and pedogenesis in exclosures in the Tigray Highlands, Ethiopia. Geoderma. In press. pp. 24.
EWNHS (Ethiopian Wildlife and Natural History Society). 1996. Important bird areas of Ethiopia: A first inventory. Addis Ababa, Ethiopia. Samayota Press.

FAO (Food and Agricultural Organization), ISRIC (International Soil Reference and Information Center), ISSS (International Soil Science Society). 1998. World reference base of soil resources. World Soil Resources Reports, Vol. 84. Rome, Italy. pp. 88.

Fay, M. 1991. An elephant (Loxodonta africana) survey using dung counts in the forests of the Central African Republic. Journal of Tropical Ecology 7: 25-36.

FDRE (Federal Democratic Republic of Ethiopia). 2001. National Agenda 21. Implementation Review Report. Environmental Protection Authority.

Fitsum, H., Pender, J., Nega,G. 1999. Land degradation in the highlands of Tigray, and strategies for sustainable land management. Socioeconomic and policy research working paper No. 25. International Livestock Research Institute, Addis Ababa, Ethiopia. pp. 78.

Foster, J. and Gaines, M. 1991. The effects of a successional habitat mosaic on a small mammal community. Ecology 72(4): 13581373.

Groombridge, B. and Jenkins, E. 1994. Biodiversity Data Sourcebook. UK. World Conservation Press.

Johnson, E. and Walter, T. 2000. Moving Toward Sustainable Forestry: Strategies for Forest Landowners. Virginia State University. Publication Number: 420-144.

Karanth, U. and Sunquist, E. 1992. Population structure, density and biomass of large herbivores in the tropical forests of Nagarahole, India. Journal of Tropical Ecology 8: 21-35.

Kindeya, G. 2003. Ecology and management of Boswellia papyearifera (Del.) Hochst. Dry forests in Tigray, Northern Ethiopia. Doctoral Dissertation. Georg-August University of Göttingen. Germany. pp. 182.

Kumar, D. 1986. Modern Concepts of Ecology. $1^{\text {st }}$ Edition. Sweden. Vikas Publishing House Pvt Ltd.

Mastewal, Y. 2006. Impact of area enclosures on density and diversity of large wild mammals and woody plants in Douga Tembien, Tigray, Ethiopia. MSc. Thesis. Mekelle University.Ethiopia. pp. 115.

Nyssen, J. 2001. Erosion processes and soil conservation in a tropical mountain catchment under threat of anthropogenic desertification: a case study from Northern 
Ethiopia. PhD Thesis, KU Leuven, Belgium. pp. 380.

Rabinowitz, R. and Walker, R. 1991. The carnivore community in a dry tropical forest mosaic in Huai Kha Khaeng Wildlife Sanctuary, Thailand. Journal of Tropical Ecology 7: 37-47.

Sarah, T. 2003. Vegetation improvement in closed areas, grazing land and protected forest in Tigray, Ethiopia. MSc. Thesis. GeorgAugust University of Göttingen. Germany. pp. 114.

Schaller, G. 1967. The deer and the tiger: A study of wildlife in India. Chicago. University of Chicago Press. pp. 370.

Schaller, G. 1972. The Serengeti Lion: A study of preypredator relations. Chicago. University of Chicago Press. pp. 480.

Smuts, G. 1978. Interrelations between predators, prey, and their environment. Bioscience 28 (5): 316-320.

Srikosamatara, S. 1993. Density and biomass of large herbivores and other mammals in a dry tropical forest, Western Thailand. Journal of Tropical Ecology 9: 33-43.

Tassew, W. 1995. Forest policy analysis and woodland clearing in a closed economy: the Ethiopian case. Wagneningen Agricultural University. The Netherlands. pp. 61.
Tefera, M. 2001. The role of area closures of the recovery vegetation in degraded hillsides of Biyo and Tiya, Central and Northern Ethiopia. MSc. Thesis. Swedish University of Agricultural Sciences. Sweden. pp. 3560 .

Teshale, A. 2003. Prevention measures for the conflicts between farmers and wild animals. Training manual. Bureau of agriculture and natural resource development of Tigray region. Unpublished. pp. 29.

TIC (Triangular Institutional Cooperation). 1999. A comparative study of common pool resource management with respect to forest and natural regeneration in Ethiopia and India. Forestry South-South links in the management of natural resources in semi arid areas.

Valone, T. and Hoffman, C. 2003. Population stability is higher in more diverse annual plant communities. Ecology Letters 6: 90-95.

Wolde, M. 2004. Impacts of land use changes on soil nutrients and erosion in Tigray, Ethiopia. MSc. Thesis. Georg-August University of Göttingen. Germany. pp. 50.

Yosef, M. 1998. A handout on introductory course in wildlife conservation and management. Debub University. Wondo Genet College of Forestry. Basic Sciences Department. Unpublished. pp. 71. 